\title{
Technical note Fluoride removal studies in water using natural materials
}

\author{
S Chidambaram, AL Ramanathan* and S Vasudevan \\ Department of Geology, Annamalai University, Annamalai Nagar 608002 \\ School of Environmental Sciences, J.N.U., New Delhi
}

\begin{abstract}
Excess fluoride in water causes health hazards to the natural environment.

The removal of fluoride was attempted using natural materials such as red soil, charcoal, brick, fly-ash and serpentine. Each material was set up in a column for a known volume and the defluoridation capacities of these materials were studied with respect to time. According to the maximum defluoridation capacity these materials were added proportionately to the vertical column. Ten $\mathrm{mg} \cdot \ell^{-1}$ of fluoride was passed through the column and the variation of fluoride removal for a known rate of flow was studied. Correlation analysis of defluoridation capacity with time was done and an attempt has been made to classify them accordingly. The study reveals that red soil has good fluoride removal capacity followed by brick, fly-ash, serpentine and charcoal.
\end{abstract}

Keywords: fluoride removal, red soil, charcoal, fly-ash, serpentine, brick

\section{Introduction}

Fluorine, a fairly common element of the earth's crust, is present in the form of fluorides in a number of minerals and in many rocks. Excess fluoride in drinking-water causes harmful effects such as dental fluorosis and skeletal fluorosis. The permissible limit of fluoride level is generally $1 \mathrm{mg} \cdot \ell^{-1}$. The high fluoride levels in drinking-water and its impact on human health in many parts of India have increased the importance of defluoridation studies. The fluoride-bearing minerals or fluoride-rich minerals in the rocks and soils are the cause of high fluoride content in the groundwater, which is the main source of drinking-water in India. The present study aimed to find a suitable low-cost environmentally friendly method for the removal of fluoride in the groundwater that is used by common man. Therefore, few natural materials such as red soil, untreated charcoal, local powdered brick, fly-ash from Neyveli (thermal power plant) and mineral serpentine were used. The ability of soil to absorb fluorine from solution has been studied by earlier researchers (Bower and Hatcher,1967; Fluker et al., 1982; Gupta et al.,1982). The capacity of fluoride removal by the individual materials was studied and accordingly two columns were set up and studied for their defluoridation capacities. The results obtained may indicate a possible solution for the removal of fluoride from a rural water supply scheme.

\section{Methodology}

Fluoride removal was done by passing water through columns, as earlier studies on stirring methods had confirmed that an increase in stirring rate increases the fluoride removal for a given temperature (Killader and Bhargava, 1993). This study is an attempt to remove fluoride by column methods using local materials. The removal rate of fluoride was tested using $25 \mathrm{~g}$ of the material (red soil, charcoal, brick powder, fly-ash and serpentine) collected in different flasks. The fly-ash of Neyveli has oxides of $\mathrm{Si}, \mathrm{Al}, \mathrm{Fe}, \mathrm{Ti}, \mathrm{Ca}, \mathrm{MgSO}_{3}$ and

\footnotetext{
* To whom all correspondence should be addressed.

E-mail: rama_au@hotmail.com

Received 6 December 2001; accepted in revised form 14 April 2003.
}

alkalies along with mixed oxides (Srinivasamorthy, 1996). The red soil used is ferruginous lateritic clay. The composition of the mineral serpentine closely corresponds to $\mathrm{Mg}_{6} \mathrm{Si}_{4} \mathrm{O}_{10}(\mathrm{OH})_{8}$. All the materials used for defluoridation were not pretreated and the size fractions taken were of $2.5 \phi$ mesh fraction. The surface character of the solid material is not considered here. The standard solution of $10 \mathrm{mg} \cdot \ell^{-1}$ fluoride was prepared by using DDW ( $\mathrm{pH} 7.2 ; \mathrm{HCO}_{3} 2.2$ $\left.\mathrm{mg} \cdot \ell^{-1} ; \mathrm{Ca} 1.1 \mathrm{mg} \cdot \ell^{-1} ; \mathrm{SO}_{4} 0.46 \mathrm{mg} \cdot \ell^{-1}\right)$. The stopper was adjusted at a standard rate of $1.5 \mathrm{~m} / \mathrm{min}$. The samples were collected at intervals of 0-15, 15-30, 30-60, 60-90 and 90-120 min. The collected solution was analysed for fluoride using an Orion fluoride ion electrode and TISAB III. According to fluoride removal capacity, two columns were set up in proportion with the adsorption capacity of these five materials and the eluent was collected at a rate of $1.5 \mathrm{me} / \mathrm{min}$ (discussed later with figures). The removal rate of the collected solution and their fluoride content was determined (Table 1). The flow rate was found to be satisfactory during preliminary trials. Larger flow rates gave high fluoride in the effluent water. Fluctuation in the flow rate was within $\pm 20 \%$. Hence the $1.5 \mathrm{~m} / \mathrm{min}$ flow rate was maintained for this study. The validity of maintaining this flow rate needs further investigation.

\begin{tabular}{|c|c|c|c|c|c|}
\hline \multicolumn{7}{|c|}{ TABLE1 } \\
\hline Time & Red soil & Charcoal & Fly-ash & Brick & Serpentine \\
\hline 15 & 0.64 & 9.05 & 3.4 & 4.7 & 3.7 \\
30 & 0.09 & 9.05 & 3.7 & 4 & 4.1 \\
60 & 0.06 & 9.1 & 4.7 & 3.7 & 4.6 \\
90 & 0.035 & 9.05 & 6 & 4 & 4.8 \\
120 & 0.029 & 9 & 7.1 & 3.9 & 5.8 \\
\hline
\end{tabular}

\section{Results}

Every solid material is a potential adsorbent. It is also reasonable to utilise the naturally occurring fluoride-seeking minerals since the 


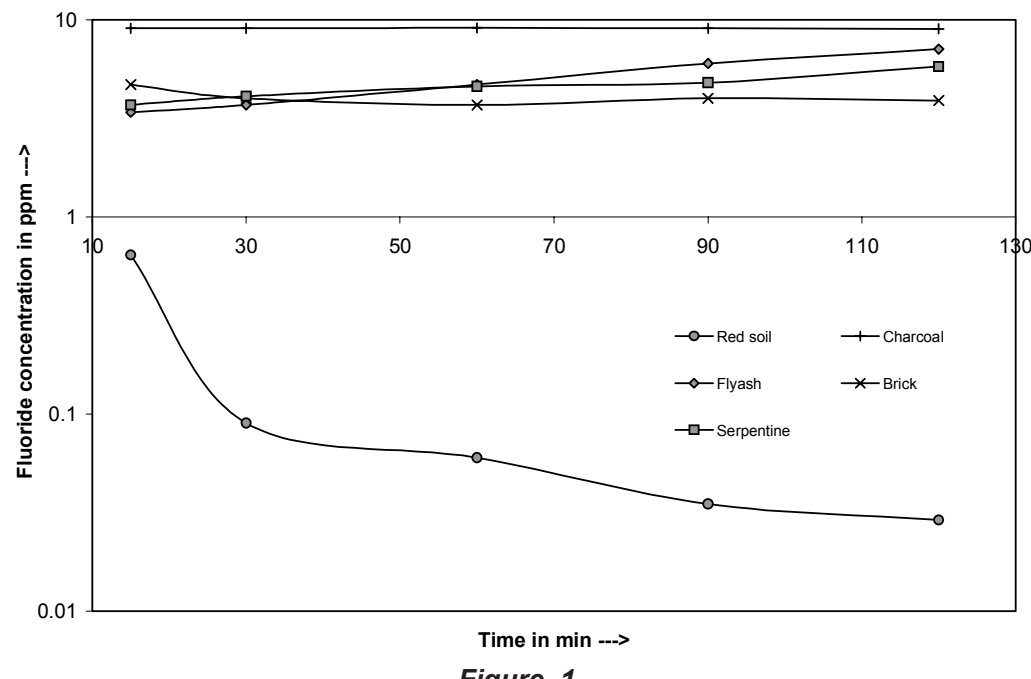

Figure 1

Fluoride removal capacities by natural materials

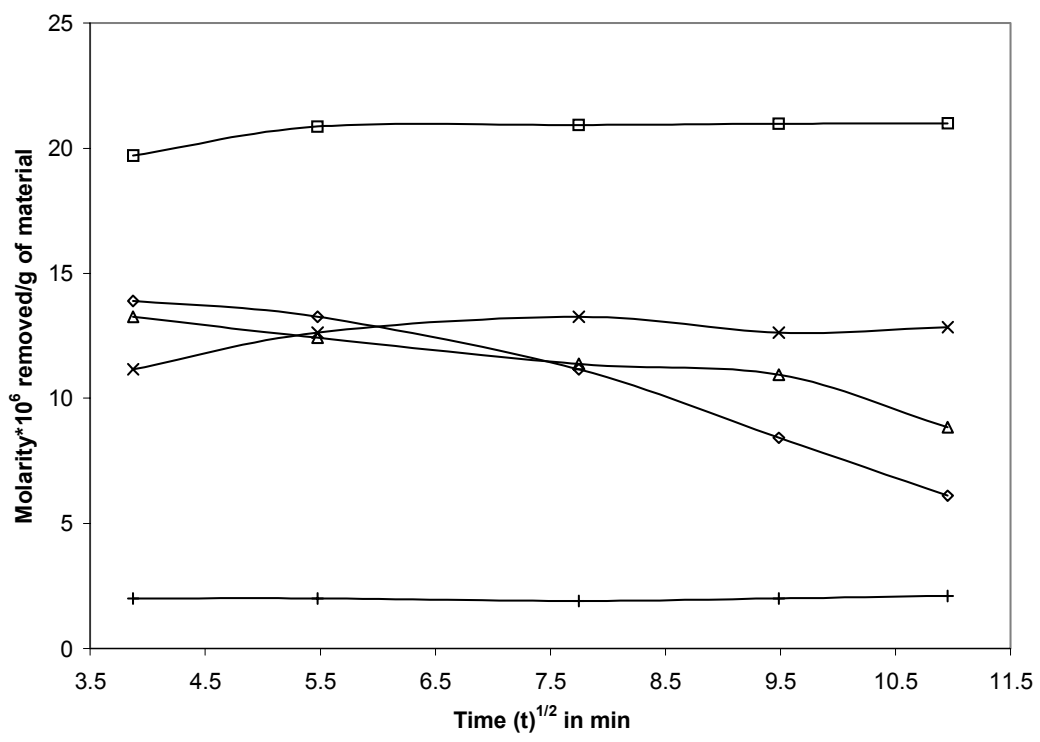

Figure 2

Fluoride removal as a function of (t)1/2

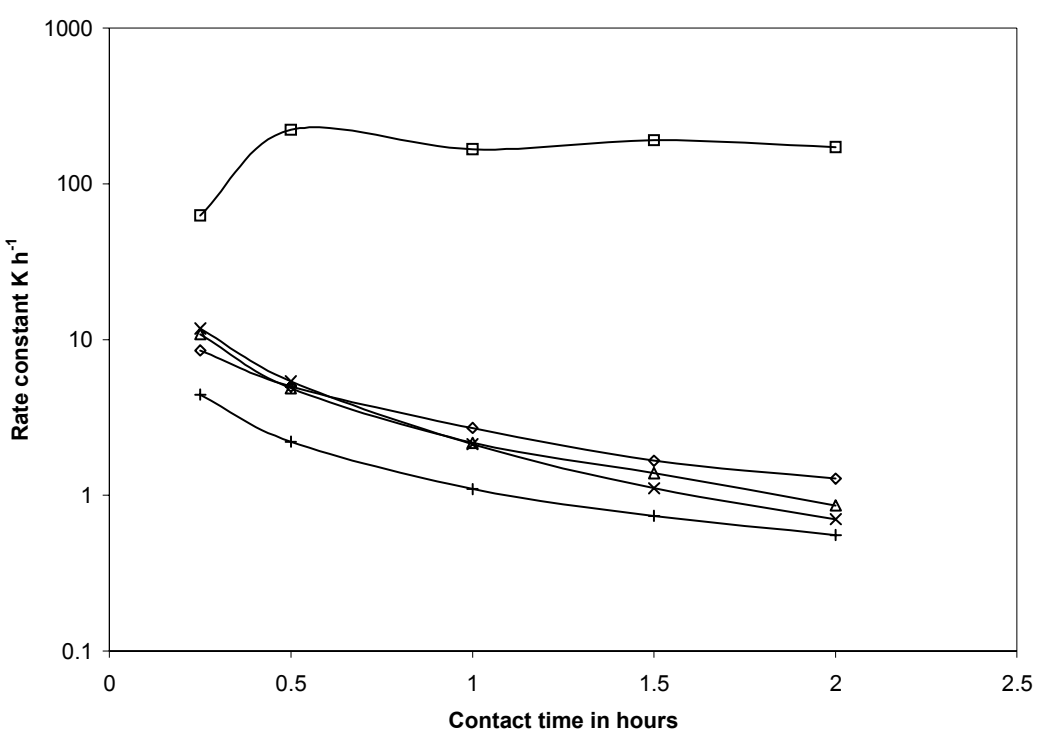

Figure 3

Fluoride adsorption rate constant as a function of contact time mineral can provide a number of fluoride-seeking cations such as $\mathrm{Ca}$ (II), $\mathrm{Mg}(\mathrm{II}), \mathrm{Al}(\mathrm{II})$, etc. Besides these cations, exchangeable anions such as $\mathrm{OH}^{-}$are present in many minerals and the proxy of $\mathrm{F}^{-}$for $\mathrm{OH}^{-}$would serve as one of the principal contributing factors for defluoridation due to the similar charge and size of these two anions. Therefore, such natural materials were used to remove the excess fluoride concentration in the natural freshwaters and were found to be effective.

Untreated charcoal (Fig. 1) seems to have no effect on the concentrations of fluoride with time and it adsorbs $0.5 \mathrm{mg} \cdot \ell^{-1}$ of fluoride. The brick and fly-ash show typically a sudden removal of fluoride from $10 \mathrm{mg} \cdot \ell^{-1}$ to $5 \mathrm{mg} \cdot \ell^{-1} .50 \%$ reduction of concentration takes place within $30 \mathrm{~min}$. Red soil adsorbs $9 \mathrm{mg} \cdot \ell^{-1}$ of fluoride immediately after 15 $\min$. After $30 \mathrm{~min}$ the fluoride decreases from 1.0 to $0.1 \mathrm{mg} \cdot \ell^{-1}$ and keeps on reducing with time up to $0.02 \mathrm{mg} \cdot \ell^{-1}$ in 90 to $120 \mathrm{~min}$. In serpentine the fluoride removal is maximal in 0 to $15 \mathrm{~min}$, i.e. 3.7 $\mathrm{mg} \cdot \bullet^{1}$; later the defluoridation capacity increases to $5.8 \mathrm{mg} \cdot \ell^{-1}$ at 90 to $120 \mathrm{~min}$ gradually. But the defluoridation capacity is less when compared to red soil.

A functional relationship

\begin{tabular}{l}
\hline$\square$ Red soil \\
+ Charcoal \\
- Flyash \\
$\rightarrow$ Brick \\
$\triangle$ Serpentine \\
\hline
\end{tabular}
common to most treatment of inter-particle diffusion is that uptake varies almost proportionately with half the power of time $V_{t}(\min )$, rather than $t$. Figure 2 shows the amount of fluoride (in moles) removed per gram of the material. It clearly shows that in the case of fly-ash and serpentine the amount removed per gram progressively decreases with half the power of time. The removal capacity of charcoal remains almost constant. But in the case of red soil and brick the initial time fraction shows a progressive increase of the fluoride removed per gram but later it remains constant. The maximum removal per gram is therefore at the beginning and later there is a gradual movement towards equilibrium. Many linear variations of amounts absorbed with $\sqrt{ }$ tare predicted for large initial fractions of reaction, which might be controlled by rates of inter-particulate diffusion.

Specific reaction rate $\mathrm{K} / \mathrm{h}$ was calculated and the rate constant was plotted against fraction of time measured $(\mathrm{h})$ (Fig. 3), from the beginning of the experiment for a constant $\mathrm{pH}$ and $\mathrm{s}=0.4 \times 10^{-2} \mathrm{mg} / \mathrm{mg}$ (ratio of fluoride ion concentration initially present to the amount of material used). The value of reaction time increased beyond $0.5 \mathrm{~h}$ and $\mathrm{K}$ decreased progressively for a given condition. This is more significant in the case of red soil and for the other materials the variation is gradual.

The plot against ratio $\mathrm{Ct} / \mathrm{Co}$ and reaction time in minutes (Fig. 4), shows that the raw charcoal shows weak fluoride removal capacity and it is almost constant over time. In the case of fly-ash 
and serpentine the removal is initially strong and at the later stages fluoride removal progressively decreases. This is evident from the increase of the $\mathrm{C}_{\mathrm{t}} / \mathrm{C}_{\mathrm{o}}$ ratio towards the maximum time fractions. Brick and red soil show similar trends exhibiting a maximum removal of up to $30 \mathrm{~min}$ whereafter the ratio tends to move gradually towards equilibrium.

\section{Discussion}

The observations reveal that after a period of $30 \mathrm{~min}$ removal of fluoride is reduced, perhaps due to saturation of the anion-exchange sites and hence the concentration of fluoride shoots up. This is also evident in the increase of the $\mathrm{HCO}_{3}$ content in water, which increases along with pH (Kulkarni et al., 1974).

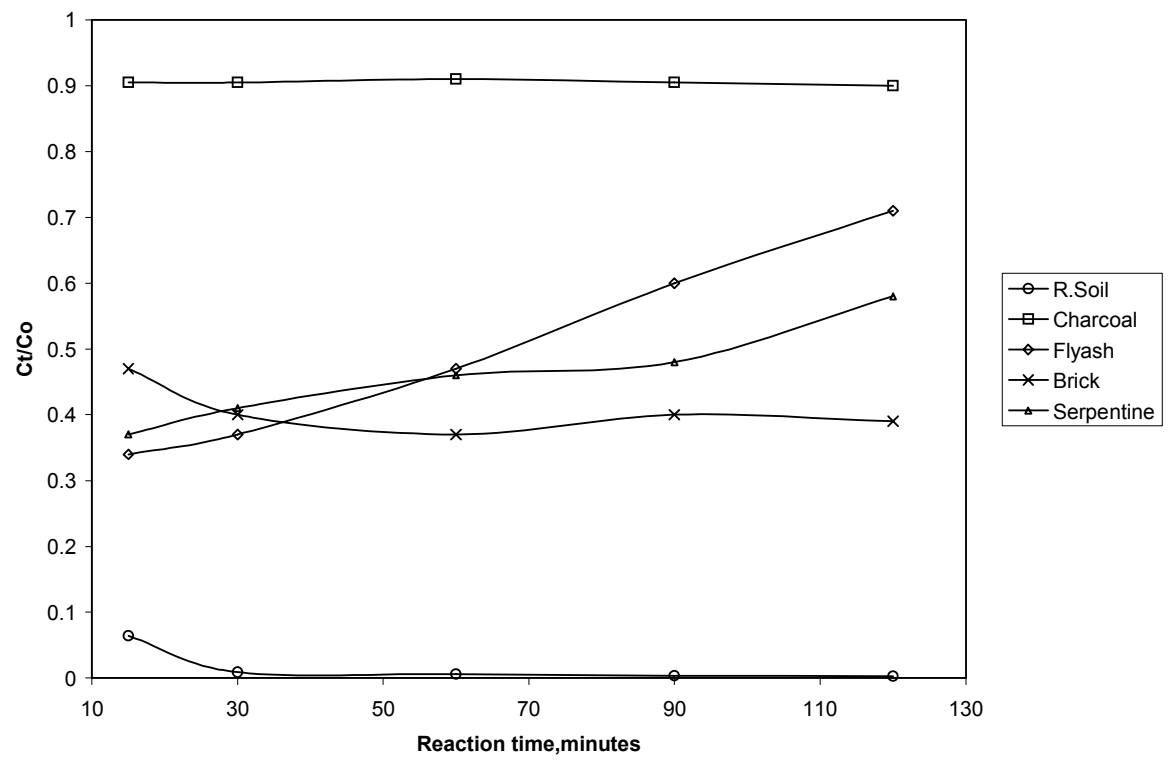

The removal of fluoride ion with $\mathrm{pH}$ variation was found to be very effective by various workers (Bulusu and Nawlakhe,1998) at lower ranges. As the decrease of $\mathrm{pH}$ probably results in the reduction of negative charges which are more at the surface of the material, adsorption is enhanced. It is interesting to note that red soil has the highest capacity to remove fluoride. The main factors here are the dominance of very fine clays, organic matter and rich in iron aluminum oxide in composition and has good anion exchange capacity. In general aluminium compounds are found to be good fluoride removers because of the reaction between $\mathrm{Al}$ and $\mathrm{F}$ molecules. Several fluoride removal methods were carried out using the aluminium-based compounds(Bulusu and Nawlakhe, 1998) natrolite, stilbite, aphophyllite (Maruthamuthu and Sivasamy, 1994) and aluminophosphate (Zhang Qianile, 1992). Adsorption studies carried out by Bower and Hatcher (1967) and Romo (1954) attributed the release of $\mathrm{OH}^{-}$(ionic radii of $1.40^{\circ} \mathrm{A}$ ), release to the exchange of clay mineral lattice by $\mathrm{F}$ (ionic radii $1.36^{\circ} \mathrm{A}$ ). The exchange of $\mathrm{F}$ for $\mathrm{OH}^{-}$ions has been studied in detail by Romo and Roy, 1957; Gillberg, 1964; Stormer and Carmichael, 1974; Munoz and Ludington, 1974. Samson (1952) has reported fluoride removal, when the F ion attacks the lattice $\mathrm{Al}$ of clay minerals causing mineral decomposition, formation of complex solid $\mathrm{F}$ phases and release of $\left(\mathrm{OH}^{-}\right)$into the solution. Since the soil is lateritic, fluoride brings $\mathrm{Al}$ and Fe ions into solution with the stoichiometric release of $\mathrm{OH}^{-}$. But the replacement of $\mathrm{OH}^{-}$by $\mathrm{F}$ is of minor significance (Huang and Jackson, 1996). $\mathrm{pH}$ shoots up to 8.5 with the $\mathrm{HCO}_{3}$ concentration going to $300 \mathrm{mg} /$. The surface sites in the Fe-rich materials can enter into complexation reactions (Jinadasa et al., 1993) with ion in solution:

$$
\begin{aligned}
& \mathrm{Fe}(\mathrm{OH})_{3}+\mathrm{M}^{\mathrm{n}+} / \mathrm{A}^{\mathrm{n}-}{ }_{(\mathrm{aq})}+\mathrm{mH}_{2} \mathrm{O}{ }_{(\mathrm{aq})} \\
& =\mathrm{FeO}-\mathrm{M}(\mathrm{OH})_{\mathrm{m}}{ }^{(\mathrm{n}-\mathrm{m}-1)}{ }_{(\mathrm{s})}+(\mathrm{m}+1) \mathrm{H}^{+}{ }_{(\mathrm{aq})}
\end{aligned}
$$

$\mathrm{M}$ and $\mathrm{A}$ represent cationic and anionic adsorbates, respectively. $\mathrm{M}(\mathrm{OH})_{\mathrm{m}}{ }^{(\mathrm{n}-\mathrm{m}-1)}$ refers to the hydrolytic species of the metal. In general the positively charged sites and negatively charged $\mathrm{F}$ ion can form surface complexes and the exchange with similar size ions is also possible. Red soil has good removal capacity because it contains both the oxides of iron and aluminium which are good fluoride removers. Brick has a moderate-to-good fluoride-removal capacity, since the brick used was also manufactured from the locally available lateritic soil. The red soil is very easily available and is also cheap.

It is evident from Fig. 4 that the rapid rate of removal of fluoride decreases markedly within $30 \mathrm{~min}$ or so to gradually approach

equilibrium which is attained almost completely after 90 min of contact between the solution and the material. The rate of adsorption/absorption or ion exchange is controlled by the rate of diffusion of fluoride in the inter-capillary pores of the particles. The mathematical treatment of inter-particulate diffusion does not lead to a simple algebraic relationship between the external solute concentration and time of the reaction event when a constant saturated external layer is maintained.

The correlation coefficient (Table 2) between the materials and time indicates a good positive correlation between fly-ash, serpentine and time which indicates that with the increase of time, the amount of $\mathrm{F}$ in the treated waters increases. Good negative correlation exists between red soil and brick, indicating that the amount of fluorine in treated waters decreases with an increase in time. But the variation of charcoal with time is less significant as it remains almost constant throughout the process with some amount of defluoridation during the initial time. Hence the materials used in this 


\begin{tabular}{|c|c|c|c|c|c|c|}
\hline \multicolumn{7}{|c|}{$\begin{array}{c}\text { TABLE2 } \\
\text { Correlation matrix of the materials used with time }\end{array}$} \\
\hline & Brick & Charcoal & Fly-ash & Red soil & Serpentine & Time \\
\hline Brick & 1 & & & & & \\
\hline Charcoal & -0.187 & 1 & & & & \\
\hline Fly-ash & -0.5226 & -0.5435 & 1 & & & \\
\hline Red soil & 0.9434 & 0.0416 & -0.636 & 1 & & \\
\hline Serpentine & -0.6222 & -0.5324 & 0.9667 & -0.6899 & 1 & \\
\hline Time & -0.591 & -0.4939 & 0.9966 & -0.691 & 0.9751 & 1 \\
\hline
\end{tabular}

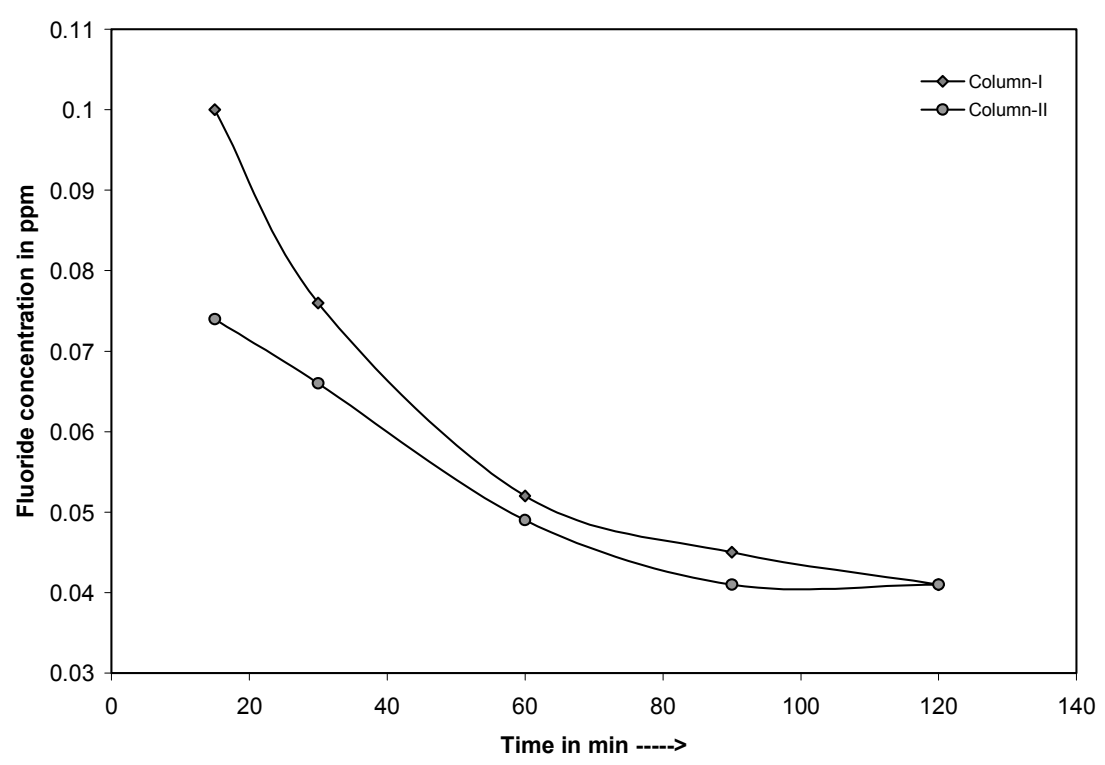

Figure 6

Fluoride removal capacities of columns

experiment can be classified into three groups:

- Materials having a negative correlation with time (red soil and brick) - GOOD

- Materials having a positive correlation with time (fly-ash and serpentine) - MODERATE

- Materials with less significant correlation with time (charcoal) - POOR

The dilution methods can be adopted to reduce the $\mathrm{F}$ concentration in groundwater but lack of water resources is the main constraint. Our preliminary experiments indicate that almost all of the naturally occurring materials used here to remove excess fluoride in water are suitable. Some have the ability to remove F over short periods of time and need regeneration immediately after $15 \mathrm{~min}$. So, approximately $25 \mathrm{~m} \ell$ can be treated within 30 min using $25 \mathrm{~g}$ volume of material. After this, new material has to be added again. Based on the above observations, two cylindrical columns each $25 \mathrm{~cm}$ in height were set up containing a combination of different materials in order to determine the efficiency of $F$ removal by these materials. Two columns were set up to determine the fluoride removal capacities for different anisotropic ratios (Leonard, 1962) for a layered sequence of same materials of different thickness. The thickness of the layers in the different columns is displayed in Fig 5. Of the two columns prepared, the second column has a higher $\mathrm{F}$ removal rate than the other. It has a $\mathrm{Kx} / \mathrm{Kz}$ ratio of 1.2844771 . The $\mathrm{Kx} / \mathrm{Kz}$ ratio for the first column is 1.0858775 . The ratio of the second column is greater than the first. The F removal rate (Fig. 6 ) is greater in Column II. It is differentiated from the $1^{\text {st }}$ column by the excess amount of brick and serpentine.

In the second column the amount of flyash and red soil was reduced, in order to increase the amount of good $\mathrm{F}$ removers in the $2^{\text {nd }}$ and $3^{\text {rd }}$ place in chosen columns. Since the raw charcoal had a meager effect on defluoridation, only a small amount of it was used in both the columns without any change.

The untreated freshwater of $10 \mathrm{mg} \cdot \ell^{-1}$ was passed through both the columns at the same time and the collected effluent was tested for fluoride ions. Column II was found to be more effective than Column I. Equilibrium was attained in Column II earlier than in Column I. When the amount of material used varies, the capacity of fluoride removal also varies along with the equilibrium time. The quantity of the materials was used in the order of removal capacities to get good results.

\section{Conclusion}

The study reveals that of the five materials used for defluoridation red soil has a good defluoridation capacity followed by brick, serpentine, fly-ash and charcoal. Near equilibrium is attained after about $30 \mathrm{~min}$ of the experiment. Maximum defluoridation occurs immediately after the experiment has started. The molarity of fluoride removed per gram is more in red soil when compared to the other materials. Red lateritic soil has the highest fluoride removal capacity because it has oxide of aluminum and iron as its major components. Both are good removers of fluoride but the red soil is found to be very effective. The column study reveals that use of the amount of materials according to fluoride removal capacity seems to be very effective. This study lacked detailed monitoring of data over a periodic time interval of $1 \mathrm{~min}$, where sequential changes can occur rapidly; further, the soils are not studied in detail for textural character and are not pretreated. Nevertheless, our study gives hope for using low-cost locally available natural material for removing excess fluoride from drinking and domestic water especially for the rural population in Asian and other developing countries. In order to improve on these techniques, further detailed investigations are needed and are being undertaken. In spite of certain technical drawbacks application of the column technique is going to be very significant since most of the rural populations live below the poverty line and cannot afford treated or bottled water for daily consumption. In this respect our study will be of great relief to those drinking-water supply systems where $\mathrm{F}$ is reported to be very high.

\section{References}

BOWER CA and HATCHER JT (1967) Adsorption of fluoride by soils and minerals. Soil Sci. 103 209-218.

BULUSU KR and NAWLAKHE WG (1998) Defluoridation of water with activated alumina - Batch operations. Indian J. Environ. Health 30 (3) 262-299. 
FLUHLER H, POLOMSKI J and BALSER P (1982) Retention and movement of fluoride in soils. J. Environ. Qual. 11 461-468.

GILLBERG M (1964) Halogen and hydroxyl content of micas and amphiboles in Swedish granite rocks. Geochim. Cosmochim. Acta 28 45-95.

GUPTA RK, CHHABRA R and ABROL IP(1982) Fluoride adsorption behavior in alkaline soils: relative roles of $\mathrm{pH}$ and sodicity. Soil Sci. 133 364-68.

HUANG PM and JACKSON HL (1996) Mechanism of reaction of neutral fluoride solution with layer silicates and oxides of soil. Soil Sci. Soc. Am. Proc. 29 661-665.

JINADASA KBPN, DISSANAYAKE CB, WEERASOORIYA SVR, SENARATNE A (1993) Adsorption of fluoride on geothite surface implications on dental epidemiology. Environ. Geol. 21 251-255.

KILLADER DJ and BHARGAVA DS (1993) Effects of temperature and stirring rate on fluoride removal by fishbone charcoal. Indian J. Environ. Health 35 (2) 81-87.

KULKARNI DN and NAWALAKHE WG (1974) Serpentine - Its limitation as a defluoridation medium. Indian J. Environ. Health 16 (2) 151-158.
LEONARD GA (1962) In: Leonards GA (ed.) Engineering Properties of Soils, Foundation Engineering. New York, McGraw Hill. 66240.

MARUTHAMUTHU and SIVASAMY (1994) Defluoridation by zeolites and aphophyllites. Fluorides 27 (2) 81-88.

MUNOZ JL and LUDINGTON SD (1974) Fluoride-hydroxyl exchange in biotite. Am. J. Sci. 274 396-413.

ROMO LA (1954) Role of lattice hydroxyls in phosphate fixation and their replacement of fluoride. J. Colloid. Chem. 9 385-392.

ROMO LA and ROY R (1957) Studies of the substitution of $\mathrm{OH}^{-}$by $\mathrm{F}$ in various hydroxylic minerals. Am. Miner. 42 165-177.

SAMSON HR (1952) Fluoride adsorption by clay minerals and hydrated aluminium. Clay Minerals 1 266-271.

SRINIVASAMORTHY K (1996) Unpublished M.Sc. dissertation. Annamali Univ., India. $87 \mathrm{pp}$.

STORMER JC and CARMICHAEL ISE (1971) Fluoride hydroxyl exchange in Apatite and Biotite. A potential geothermometer. Contrib. Miner. Petrol 31 167-189.

ZHANG QIANILE (1992) Aluminophosphate for the defluoridation of potable water. Environ. Int. 18 307-310. 
